Supporting Information

\title{
Rationally Designed Polymer Conjugate for Tumor-Specific Amplification of Oxidative Stress and Boosting Anti-tumor Immunity
}

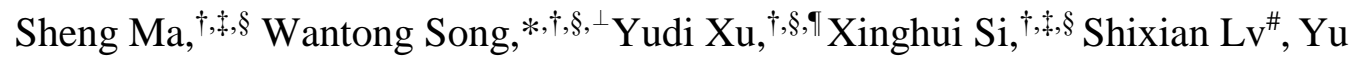
Zhang, ${ }^{\dagger, \S}$ Zhaohui Tang, ${ }^{\dagger, \dagger, \S}$ Xuesi Chen $*, \dagger, \ddagger, \S$

${ }^{\dagger}$ Key Laboratory of Polymer Ecomaterials, Changchun Institute of Applied Chemistry, Chinese Academy of Sciences, Changchun, 130022, China

\$ University of Science and Technology of China, Hefei, 230026, China

$\S$ Jilin Biomedical Polymers Engineering Laboratory, Changchun, 130022, China

${ }^{\perp}$ State Key Laboratory of Molecular Engineering of Polymers (Fudan University), Shanghai, 200433, China

II University of Chinese Academy of Sciences, Beijing, 100039, China

\#Department of Bioengineering, Molecular Engineering and Sciences Institute, University of Washington, Seattle, 98195, United States

Corresponding authors:

*Email: wtsong@ciac.ac.cn

*Email: xschen@ciac.ac.cn

Materials. $\gamma$-benzyl-L-glutamate- $N$-carboxyanhydride (BLG-NCA) was synthesized based on our previous work. ${ }^{1}$ 3-(4,5-Dimethyl-thiazol-2-yl)-2,5-diphenyl tetrazolium bromide (MTT), 2',7'-Dichlorofluorescin Diacetate (DCFH-DA), cinnamaldehyde (CA), 4',6-diamidino-2- phenylindole dihydrochloride (DAPI) and poly (ethylene glycol) monomethyl ether (mPEG, $\left.M_{\mathrm{n}}=5000\right)$ were provided by Shanghai SigmaAldrich Co., LTD. Anhydrous $N^{\prime} N$-dimetylformamide (DMF), chloroform and dichloromethane (DCM) was obtained through vacuum distillation. 
Diisopropylcarbodiimide (DIC) and 4-dimethylaminopyridine (DMAP) was provided by Beijing J\&K Co., LTD. 5-chloro-1-pentyne, 15-crown-5, 4-formylphenylborate pinacol ester (2) and anhydrous tetrahydrofuran (THF) were provided by Beijing Energy Chemical Co., LTD. Sodium diformylamide, tri-n-octylamine and sodium iodide were provided by Adamas. p-tosyl chloride was provided by Shanghai Aladdin Co., LTD. Annexin V-FITC apoptosis detection kit was purchased from Shanghai Beyotime Biotechnology Co., LTD. ATP assay kit was purchased from Jiangsu KeyGEN Biotechnology Co., Ltd. Other reagents and solvents were provided by Sinopharm Chemical Reagent Co., LTD.

Characterization. ${ }^{1} \mathrm{H}$ NMR spectrum were characterized by Bruker AV-500 or Bruker AV-300 NMR spectrometer. Electrospray ionization mass spectroscopy (ESI-MS) was performed on a Bruker APEX-IV Fourier transform mass spectrometer. Drug release was calculated by high performance liquid chromatography (HPLC), which is made up of a Waters 2414 Refractive Index Detector, a Waters 515 HPLC pump and a reversephase C-18 column (Symmetry®). Dynamic light scattering (DLS) was used to characterize the sizes of the self-assemble nanoparticles. A JEOL JEM-1011 (Tokyo, Japan) was used to obtain transmission electrol microscopy (TEM) images. Histological alterations were observed by optical microscope (Nikon Eclipse Ti, Optical Apparatus Co., Ardmore, PA, USA). Gel permeation chromatography (GPC) measurements were performed on a waters GPC system (Waters Ultrahydrogel Linear column, 1515 HPLC pump with 2414 Refractive Index detector) using phosphate buffer (0.2 M, pH 7.4) as the eluent (flow rate: $1 \mathrm{~mL} / \mathrm{min}$ ). All the immunofluorescence slides and cellular uptake slides were pictured through a confocal laser scanning microscope (CLSM, Carl Zeiss LSM 700, Germany). The ex vivo fluorescence images of major organs and tumors were picture with Davinch Invivo Hr imaging system (DavinchK, Korea).

Cell culture. The murine colorectal cancer CT26 cells and murine breast cancer 4T1 cells were used to carry out the in vitro and in vivo studies and incubated at $37{ }^{\circ} \mathrm{C}$ in an atmosphere of $5 \%$ CO2. Dulbecco's modified Eagle's medium (DMEM) (containing 
$10 \%$ fetal bovine serum (FBS), $50 \mathrm{U} / \mathrm{mL}$ penicillin and $50 \mathrm{U} / \mathrm{mL}$ streptomycin was used to culture cells.

Synthesis of carboxyl-terminated acetal modified CA derivative (1). As described in Scheme S1A, tris-(hydroxymethyl)ethane (5.45 g, $45.5 \mathrm{mmol})$, cinnamaldehyde (6 $\mathrm{g}, 45.5 \mathrm{mmol})$, and p-toluenesulfonic acid (78.3 $\mathrm{mg}, 0.455 \mathrm{mmol})$ were dissolved in 40 $\mathrm{mL}$ of anhydrous benzene stirring with $0.5 \mathrm{~g}$ molecular sieves. The reaction was maitained for $24 \mathrm{~h}$ at $60{ }^{\circ} \mathrm{C}$, following terminated by $100 \mu \mathrm{L}$ of anhydrous trimethylamine. Filtration through G4 funnel, the filtrate was added $10 \mathrm{~g}$ silica gel and evaporated using a rotary evaporator. The acetal modified CA derivative was obtained from column chromatography (hexane/ethyl acetate $=7 / 3$ ). The structure was determined by ${ }^{1} \mathrm{H}$ NMR using DMSO- $d_{6}$ as the solvent, ESI-MS was also used to characterize acetal modified CA derivative, $[\mathrm{M}+\mathrm{H}]=235.2,[\mathrm{M}+\mathrm{Na}]=257.2($ Figure S1).

Acetal modified CA derivative (1.0 g, $4.27 \mathrm{mmol})$ and succinic anhydride $(2.14 \mathrm{~g}, 21.36$ mmol) were dissolved in anhydrous DCM (40 mL), then DMAP $(0.296 \mathrm{~g}, 2.14 \mathrm{mmol})$ was added in ice bath. The reaction solution was gradually warmed up to room temperature and maintained at room temperature for $48 \mathrm{~h}$.The mixture was diluted with DCM (200 mL) and washed with brine, followed washed with DI water. The organic phase was dried over $\mathrm{Na}_{2} \mathrm{SO}_{4}$. The obtained filtrate was added $2 \mathrm{~g}$ silica gel and evaporated using a rotary evaporator. The carboxyl-terminated acetal modified CA derivative (1) was obtained through column chromatography (DCM/MeOH $=100: 1$ to 15:1). The structure was determined by ${ }^{1} \mathrm{H}$ NMR using DMSO- $d_{6}$ as the solvent, ESIMS was also used to characterize carboxyl-terminated acetal modified CA derivative (1), $[\mathrm{M}+\mathrm{H}]=334.4($ Figure $\mathrm{S} 2)$.

Synthesis of 5-isocyanopent-1-yne (3). 5-Isocyanopent-1-yne was synthesized according to the literature. ${ }^{2}$ As described in Scheme S1B, we first synthetized 5formylaminopent-1-yne. Typically, 5-chloro-1-pentyne (10.0 g, $98.0 \mathrm{mmol})$, sodium diformylamide $(11.17 \mathrm{~g}, 107.8 \mathrm{mmol})$, sodium iodide $(0.441 \mathrm{~g}, 9.8 \mathrm{mmol})$ and 15 crown-5 (2.16 g, $9.8 \mathrm{mmol})$ were dissolved in anhydrous acetonitrile. The mixture was 
refluxed for $12 \mathrm{~h}$ before filtration of the salts and rotary evaporation of acetonitrile. Afterward, $\mathrm{KOH}(0.22 \mathrm{~g}, 3.9 \mathrm{mmol})$ and methanol $(220 \mathrm{~mL})$ were added, and the mixture was stirred at room temperature for $20 \mathrm{~min}$. After removal of methanol, ethyl acetate $(200 \mathrm{~mL})$ was added, and the organic phase was washed with brine, combined, and dried. 5-formylaminopent-1-yne was obtained as yellow oil after complete removal of ethyl acetate. The structure was determined by ${ }^{1} \mathrm{H} \mathrm{NMR}$ using $\mathrm{CDCl}_{3}$ as the solvent (Figure S3).

5-formylaminopent-1-yne (1.2 g, $10.81 \mathrm{mmol})$, p-tosyl chloride (4.12 g, $21.62 \mathrm{mmol})$, and tri-n-octylamine $(7.65 \mathrm{~g}, 21.62 \mathrm{mmol})$ were added into a $25 \mathrm{~mL}$ round-bottom flask and heated under stirring to $80{ }^{\circ} \mathrm{C}$ for $1.5 \mathrm{~h}$. 5-isocyanopent-1-ene (3) can be distilled out under reduced pressure. The structure was determined by ${ }^{1} \mathrm{H} \mathrm{NMR}$ using $\mathrm{CDCl}_{3}$ as the solvent (Figure S4).

Synthesis of PBCA (4). As described in Figure 1A, carboxyl terminal cinnamaldehyde derivative (3) (100mg, 0.3mmol), 4-formylphenylboronic acid pinacol ester (76.4mg, $0.33 \mathrm{mmol})$ and 5-isocyanopent-1-yne $(31.3 \mathrm{mg}, 0.33 \mathrm{mmol})$ were dissolved in $0.5 \mathrm{~mL}$ $\mathrm{CHCl}_{3}$. The reaction was maintained at $30{ }^{\circ} \mathrm{C}$ for $72 \mathrm{~h}$. The reaction mixture was diluted with $50 \mathrm{~mL}$ of DCM and washed with brine. The organic phase was dried over anhydrous $\mathrm{MgSO}_{4}$ and purified by column chromatography using DCM/EA (10:1) as an eluent to obtain a yellow viscous liquid. The structure was determined by ${ }^{1} \mathrm{H}$ NMR using DMSO- $d_{6}$ as the solvent, ESI-MS was also used to characterize CA derivative 4, $[\mathrm{M}+\mathrm{H}]=660.4,[\mathrm{M}+\mathrm{Na}]=682.4($ Figure S5).

Synthesis of poly (L-glutamic acid)-graft-poly (ethylene glycol) monomethyl ether/ azidopropylamine (PLG-N3) (5). To synthesize TSEOP, poly (L-glutamic acid)-graftpoly (ethylene glycol) monomethyl ether/ azidopropylamine (PLG-N 3 ) was first synthesized. As described in Scheme S1C, poly (L-glutamic acid)-graft-poly (ethylene glycol) monomethyl ether (PLG-g-mPEG) (200mg, $0.5 \mathrm{mmol}$, calculated by carboxyl groups), which was prepared as previously described, ${ }^{3} \mathrm{HOBt}(40.5 \mathrm{mg}, 0.3 \mathrm{mmol})$ and DPEA (38.7 mg, $0.3 \mathrm{mmol}$ ) were dissolved in $5.0 \mathrm{~mL}$ anhydrous DMF, and stirred at room temperature for $30 \mathrm{~min}$ to activate carboxyl groups. Then azidopropylamine (14 
$\mathrm{mg}, 0.15 \mathrm{mmol}$ ) was injected into the reaction mixture, and keep stirring for another 72 h. Once the reaction was over, the mixture solution was directly dialysis against DI water for $48 \mathrm{~h}$ in dark, and PLG-N 3 was obtained after lyophilization (Figure S6).

Synthesis of TSEOP (6). As described in Figure 1A, PLG-N 3 (200mg, 0.14mmol, calculated by azido groups), PBCA (4) (91 mg, $0.14 \mathrm{mmol}$ ) and PMDETA (2.4mg, $0.014 \mathrm{mmol}$ ) were dissolved in $10.0 \mathrm{~mL}$ anhydrous DMF, and ventilated for $30 \mathrm{~min}$. Then the mixture was frozen and thawed in vacuum for three cycles. After that, of $\mathrm{CuBr}$ (12.9 $\mathrm{mg}, 0.009 \mathrm{mmol}$ ) was added into the mixture solution in nitrogen atmosphere, following sealed and stirred at room temperature for 24 hours. After reaction, the mixture was directly dialysis against DI water $(\mathrm{pH} 8.0)$ for $96 \mathrm{~h}$ in dark. A flaxen solid was obtained after lyophilization (Figure S7).

Synthesis of poly (L-glutamic acid)-graft-poly (ethylene glycol) monomethyl ether/ CA derivative 2 (P-CA). As described in Scheme S1D, PLG-g-mPEG (200mg, 0.5mmol, calculated by carboxyl groups), EDCI (57.6 mg, $0.3 \mathrm{mmol}$ ), DMAP (36.6 mg, $0.3 \mathrm{mmol})$ and acetal modified CA derivative ( $35 \mathrm{mg}, 0.15 \mathrm{mmol})$ were dissolved in 5.0 $\mathrm{mL}$ anhydrous $\mathrm{DMF}$, and stirred at room temperature for $48 \mathrm{~h}$. After reaction, the mixture was precipitated into excess cold diethyl ether and then was re-dissolved in DMF and directly dialysis against DI water ( $\mathrm{pH} 8.0)$ for $48 \mathrm{~h}$ in dark, and P-CA was obtained after lyophilization (Figure S11).

Synthesis of poly (L-glutamic acid)-graft-poly (ethylene glycol) monomethyl ether/ 4-(hydroxymethyl)phenylboronic acid (P-PBA). As described in Scheme S1E, PLGg-mPEG (200mg, 0.5mmol, calculated by carboxyl groups), EDCI (57.6 mg, 0.3 mmol), DMAP (36.6 mg, 0.3mmol) and 4-(hydroxymethyl)phenylboronic acid pinacol ester $(35 \mathrm{mg}, 0.15 \mathrm{mmol})$ were dissolved in $5.0 \mathrm{~mL}$ anhydrous DMF, and stirred at room temperature for $48 \mathrm{~h}$. After reaction, the mixture was directly dialysis against DI water for 48h. P-PBA was obtained after lyophilization (Figure S12).

Synthesis of Cy5-labeled TSEOP (Cy5-TSEOP). TSEOP (50 mg) and Cy5-NHS (5 $\mathrm{mg}$ ) were dissolved in DMF (5 mL). After stirring at room temperature for $2 \mathrm{~d}$, the 
mixture was directly dialyzed against DI water $(\mathrm{MWCO}=3500 \mathrm{Da})$ and lyophilized to obtain the final product.

Solution behavior of TSEOP. The nano-micelles of TSEOP were formed by directly dispersed in phosphate buffered (PB). Dynamic light scattering (DLS) and TEM were used to characterize the size and morphology of the TSEOP nano-micelles. The morphology changes of TSEOP nano-micelles were evaluated after TSEOP incubated with $\mathrm{pH} 6.8 \mathrm{~PB}$ for 0 and $24 \mathrm{~h}$.

In vitro ROS Elevation and GSH Depletion. To further investigate the ROS elevation in CT26 cells, DCFH-DA was used as a fluorescent probe to observe the intracellular ROS. Cells were treated with different formulations for $24 \mathrm{~h}$ and then incubated with DCFH-DA, followed by nuclei staining with DAPI.

To evaluate the GSH-depleting ability of different formulations, the GSH concentration in CT26 cells after treatments was further investigated by using the GSH/GSSG Assay Kit. After incubation with different formulations or various concentrations of TSEOP at different CA concentration for $24 \mathrm{~h}$, the GSH level was quantitatively measured.

In vitro drug release. TSEOP (containing $0.5 \mathrm{mg} \mathrm{CA}$, dissolved in $5 \mathrm{~mL}$ buffer) was added to a dialysis bag (MW 3,500 Da), and then immersed in $45 \mathrm{~mL}$ buffer under shaking ( $90 \mathrm{rpm}$ ) at $37^{\circ} \mathrm{C}$ at four conditions: $\mathrm{pH} 7.4(10 \mathrm{mM}$, phosphate buffered saline (PBS)), pH 6.8 (10 mM, PBS), pH 6.8 with $10 \mu \mathrm{M} \mathrm{H}_{2} \mathrm{O}_{2}(10 \mathrm{mM}, \mathrm{PBS})$ and pH 6.8 with $10 \mathrm{mM} \mathrm{H}_{2} \mathrm{O}_{2}(10 \mathrm{mM}$, PBS), separately. At each desired time point, $5.0 \mathrm{~mL}$ of the release solution was withdrawn and $5.0 \mathrm{~mL}$ of the same fresh buffer was replenished, respectively. The release tests were repeated in triplicate under the same conditions. The amount of released CA was measured by HPLC. As for mobile phase, water and acetonitrile $(80 / 20, v / v)$ were selected at a flow rate of $1.0 \mathrm{~mL} / \mathrm{min}$ under isocratic regime.

Cellular Internalization. The cellular internalization of TSEOP was investigated with flow cytometry. CT26 cells were seeded into 6-well plates at a density of $3 \times 10^{5}$ cells per well. After $24 \mathrm{~h}$ incubation, the medium was replaced with fresh medium containing Cy5-TSEOP at an equivalent dosage of TSEOP $(50 \mu \mathrm{g} / \mathrm{mL})$ and incubated at $37^{\circ} \mathrm{C}$ for 
$1 \mathrm{~h}$ or $3 \mathrm{~h}$. Then the cells were washed with PBS twice, collected and suspended in PBS. The cellular fluorescence was assayed with a Guava EasyCyteTM 12 Flow Cytometer (Millipore, Billerica, MA, USA). All experiments were repeated in triplicates.

In vitro cytotoxicities assays. The in vitro cytotoxicities of free $\mathrm{CA}$, free $\mathrm{PBA}$, free PBA with free CA, P-PBA, P-CA, P-CA with P-PBA and TSEOP were evaluated using MTT assay. 8000 CT26 or 4T1 cells were seeded per well with $200 \mu \mathrm{L}$ of complete culture medium to 96-well culture plates. After overnight incubation, fresh DMEM containing different formulations $(0-100 \mathrm{ug} / \mathrm{mL} \mathrm{CA})$ was added after removing the culture medium. MTT solution was injected after incubation for $24 \mathrm{~h}$. After another 4 h incubation, $150 \mu \mathrm{L}$ of DMSO was injected to replace the medium. The absorbances of each well were measured at $490 \mathrm{~nm}$ on a Bio-Rad 680 microplate reader. The relative cell viability (\%) was determined through comparing the absorbance values of sample wells with that of control wells.

Immunogenic cell death and cytotoxicity of TSEOP. Flow cytometry analysis was used for the surface detection of CRT. CT26 cells were seeded in the 6-well plate at a density of $3 \times 10^{5}$ cells/well. After $10 \mathrm{~h}$ pre-incubation, the cells were treated with free CA, P-CA or TSEOP at an equal CA concentration of $100 \mathrm{ug} / \mathrm{mL}$ for $4 \mathrm{~h}$. Then the cells were washed with cold PBS and further incubated with Cy5 labelled CRT antibody for 45min. After that, the cells were washed with cold PBS, collected and suspended in PBS. Finally, the surface fluorescence was assayed with a Guava EasyCyteTM 12 Flow Cytometer (Millipore, Billerica, MA, USA). All experiments were repeated in triplicates.

Extracellular secretion of ATP was evaluated with a commercially available ATP assay kit. Briefly, CT26 cells were seeded in the 6 -well plate at a density of $2.5 \times 10^{4}$ cells/well. After incubated overnight, the cells were treated with PBS, free CA, P-CA or TSEOP at an equal CA concentration of $30 \mathrm{ug} / \mathrm{mL}$ for $24 \mathrm{~h}$. Then the culture medium was collected and the concentration of ATP was evaluated with an ATP assay kit according to manufacturer's instructions. 
For evaluating intracellular HMGB1, CT26 cells were seeded on a live cell imaging glass bottom dish with a density of $3 \times 10^{5}$ cells/well. After incubated overnight, the cells were treated with PBS, free CA, P-CA or TSEOP at an equal CA concentration of 30 $\mathrm{ug} / \mathrm{mL}$ for $24 \mathrm{~h}$. After that, the cells were washed with PBS twice. Then, the cells were fixed with $4 \%$ paraformaldehyde for $20 \mathrm{~min}$ and permeabilized with $0.1 \%$ Triton $\mathrm{X}$ 100 for $10 \mathrm{~min}$, followed by incubation with with 5\% fetal bovine serum in PBS for 30 min. Next, the cells were incubated with primary HMGB1 antibody for $1 \mathrm{~h}$, and then incubated with an Cy5-conjugated secondary antibody for $30 \mathrm{~min}$ after three washes with PBS. Finally, the cells were stained with DAPI and examined by CLSM.

DC activation in vitro. To evaluate DC activation in vitro, bone marrow-derived dendritic cells (BMDCs) were obtained from the bone marrow of 6-week-old BALB/c mice. CT26 cells were first treated with free CA, P-CA or TSEOP for $24 \mathrm{~h}$ at a CA concentration of $30 \mathrm{ug} / \mathrm{mL}$. Afterwards, $4 \times 10^{5}$ BMDCs were cultured with $1.5 \mathrm{~mL}$ fresh medium and $1.5 \mathrm{~mL}$ tumor cells cultured medium obtained from different pretreated CT26 cells groups. After that, the BMDCs were collected and stained with anti-CD11cPE and anti-CD80-PerCP/Cy5.5 antibodies. The activation of DCs was examined by using flow cytometry measurement.

Pharmacokinetics of TSEOP. 3 Female SD rats (average weight $220 \mathrm{~g}$ ) were used for evaluated the the performances of TSEOP in pharmacokinetics utilizing Cy5-TSEOP. The mice were kept in specific pathogen free (SPF) animal lab and operated according to the guidelines approved by the Animal Care and Use Committee of Jilin University. Cy5-TSEOP was administered via tail vein at an equivalent dosage $(10 \mathrm{mg} / \mathrm{kg}$, based on CA). Blood samples were collected from the orbital cavity through capillary tube at each desired time point ( $5 \mathrm{~min}, 0.5,1,2,4,8,12$ and $24 \mathrm{~h}$ ), mixed with heparin sodium, and the plasmas were obtained after centrifugation. The concentration of Cy5-TSEOP were determined by fluorescence spectrometry $(\lambda \mathrm{ex}=649 \mathrm{~nm}, \lambda \mathrm{em}=670 \mathrm{~nm}) .{ }^{4}$ The half-life of the drug $\left(\mathrm{t}_{1 / 2}\right)$ and area under the drug concentration-time curve from 0 to $24 \mathrm{~h}$ in plasma $\left(\mathrm{AUC}_{0-\mathrm{t}}\right)$ were calculated using PKSolver [54]. 
Biodistribution of TSEOP. Two 6-8 weeks old female BALB/c mice were subcutaneously embedded with CT26 cells $\left(1 \times 10^{6}\right)$ into the abdomen. Once the tumor volumes reached 100-150 $\mathrm{mm}^{3}$, Cy5-TSEOP was intravenously injected into the mice at an equivalent dosage (10 mg/kg, based on CA). At $24 \mathrm{~h}$ post injection, the tumor tissues and major organs (heart, liver, spleen, lung and kidney) were collected. The distribution of TSEOP in major organs was quantitatively visualized by Davinch-Invivo HR imaging system (Davinch, Korea) with the excitation wavelength at $650 \mathrm{~nm}$ and the emission wavelength at $680 \mathrm{~nm}$.

In vivo antitumor efficiency. The female $\mathrm{BALB} / \mathrm{c}$ mice (6-8 weeks old) were subcutaneously embedded CT26 or 4T1 cells $\left(2 \times 10^{6}\right)$ into abdomen. Once the tumor volume reached approximately $100 \mathrm{~mm}^{3}$, the mice were assigned at random $(n=5)$ and received different treatments. The mice received treatments every three days and received four treatments in total. Body weights and tumor volumes were recorded every other day. The day when the treatment started was designated as day 0 . The tumor volume was measured with a calipers, which was calculated as followings: tumor volume $(V)=\mathrm{a} \mathrm{b}^{2} / 2$, where $\mathrm{a}$ is the major axis and $\mathrm{b}$ is the minor axis of the tumor. The tumor suppression rate (TSR) was calculated as followsfollowing: TSR $(\%)=\left[\left(V_{\mathrm{c}}\right.\right.$ $\left.\left.-V_{\mathrm{x}}\right) / V_{\mathrm{c}}\right] \times=100 \%$, where $V_{\mathrm{c}}$ represents the mean tumor volume of the PBS group and $V_{\mathrm{x}}$ represents the mean tumor volume of the treatment group.

Immunohistochemical and immunofluorescence analyses. By the end of the therapeutic experiment, mice were sacrificed, major organs and tumors were obtained. All major organs and some excised tumors soaked into 4\% PBS buffered paraformaldehyde for $24 \mathrm{~h}$, then soaked into $15 \%(\mathrm{w} / \mathrm{v})$ and $30 \%(\mathrm{w} / \mathrm{v})$ PBS-buffered sucrose solution successively, and finally all the organs and tumor tissues kept in $30 \%$ (w/v) PBS-buffered sucrose solution before use. To obtain paraffin slices, the paraffin embedded tissues were cut into $5 \mu \mathrm{m}$ thickness. Histological alterations of tumors and the major organs were evaluated by staining the paraffin slices with hematoxylin and eosin (H\&E). TUNEL staining was also used to evaluate apoptosis of tumor tissues, the 
procedures were consistent with the manufacturer's protocol (keygen biotech). All the immunofluorescence staining slides were analyzed through a CLSM.

Flow cytometry analysis of the tumor tissues. The female BALB/c mice (6- 8 weeks old) were subcutaneously embedded CT26 or 4T1 cells $\left(2 \times 10^{6}\right)$ into abdomen. Once the tumor volume reached approximately $100 \mathrm{~mm}^{3}$, the mice were assigned at random $(n=3-4)$ and received the same treatment as previously described. Mice were sacrificed at day 16. The obtained tumors were used to prepare single-cell suspensions. The single-cell suspensions were further incubated with various antibodyes against the immune cells (Table $\mathrm{S} 1$ ). Flow cytometry analysis was carried out on a flow cytometry machine (BD FACS Canto II). The results were analyzed with the FlowJo.

Vaccination and re-challenge study. Female BALB/c mice (6-8 weeks old) were divided into 3 groups in radom with 6 mice in each group, and immunized twice with PBS, fresh CT26 cells and CT26 cells pre-treated with TSEOP (TSEOP-CT26 cells) on day -7 and day -1 by subcutaneous injection into mouse right axilla. For the TSEOPCT26 cells group, $6 \times 10^{6}$ CT26 cells were firstly seeded in $150 \mathrm{~mm}$ cell culture dish, and treated with TSEOP at a CA concentration of $100 \mu \mathrm{g} / \mathrm{mL}$ for $24 \mathrm{~h}$; the CT26 cells were collected and suspended in $600 \mu \mathrm{L}$ sterile PBS for 6 mice injection. On day 0 , all the mice were inoculated with $1 \times 10^{6} \mathrm{CT} 26$ cells into the left axilla. The re-challenged tumor volumes were recorded every other day. The tumor volume was calculated with the same method as previously described.

Hematological analysis. In order to investigate the safety of the treatments, three mice in each group of murine colorectal model (CT26) were sacrificed for blood chemistry analysis on day 17, and serum was collected. The hematological parameters were analyzed including alanine transaminase (ALT), aspartate aminotransferase (AST), uric acid (UA) and creatinine (CREA).

Statistical analysis. Experiments were performed at least three times and results were expressed as means \pm SD. Statistical significances were analyzed using the Student's ttest and one-way analysis of variance (ANOVA), and differences between the test and 
control groups were judged to be significant at ${ }^{*} p<0.05$, very significant at $* * p<0.01$ and extremely significant at $* * * p<0.001$.

A

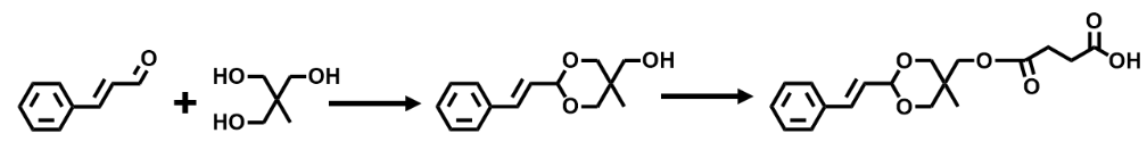

B

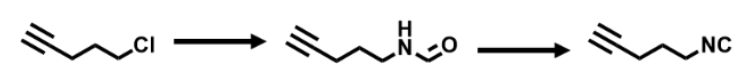

C

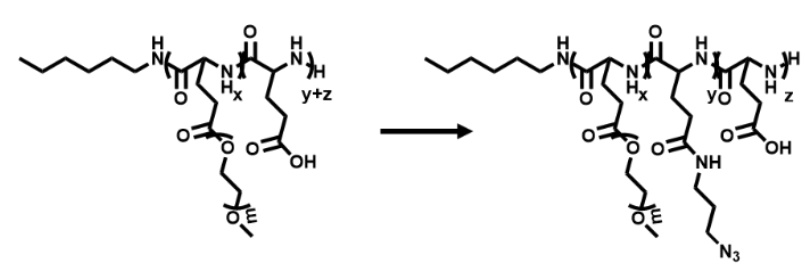

D

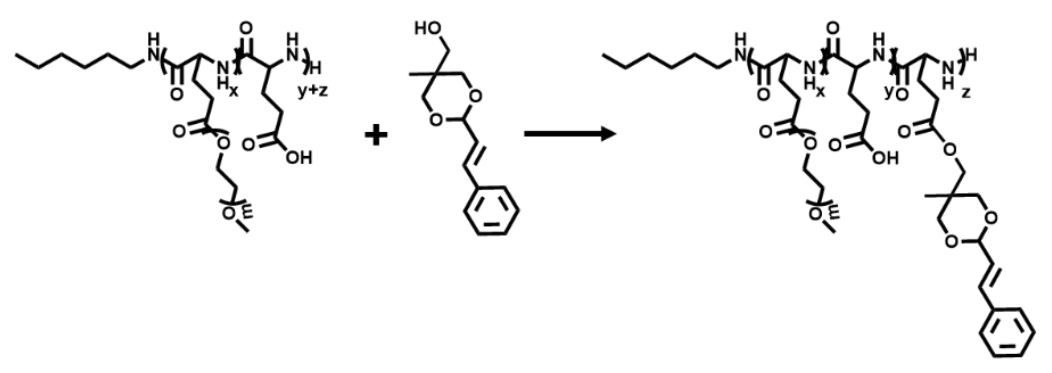

E

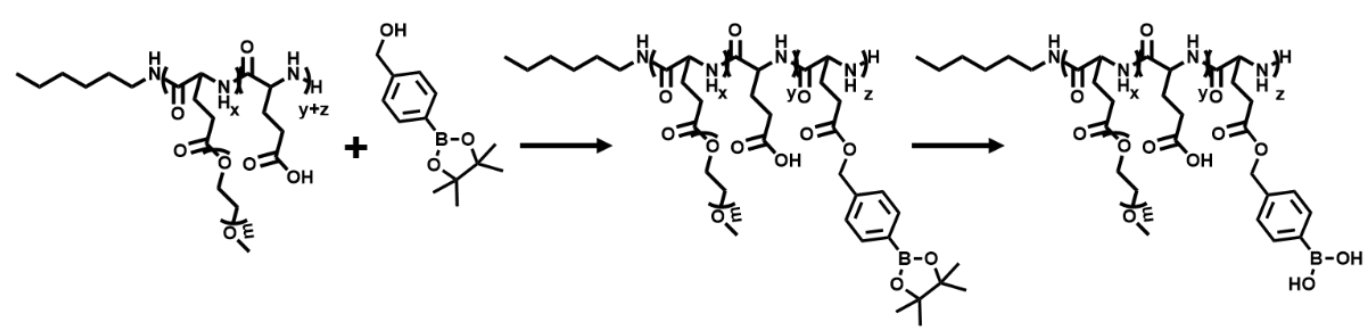

Scheme S1. Synthesis routes for (A) carboxyl-terminated acetal modified CA derivative (1), (B) Synthesis of 5-isocyanopent-1-yne (3), (C) PLG-N3 (5), (D) P-CA and (E) P-PBA, respectively. 

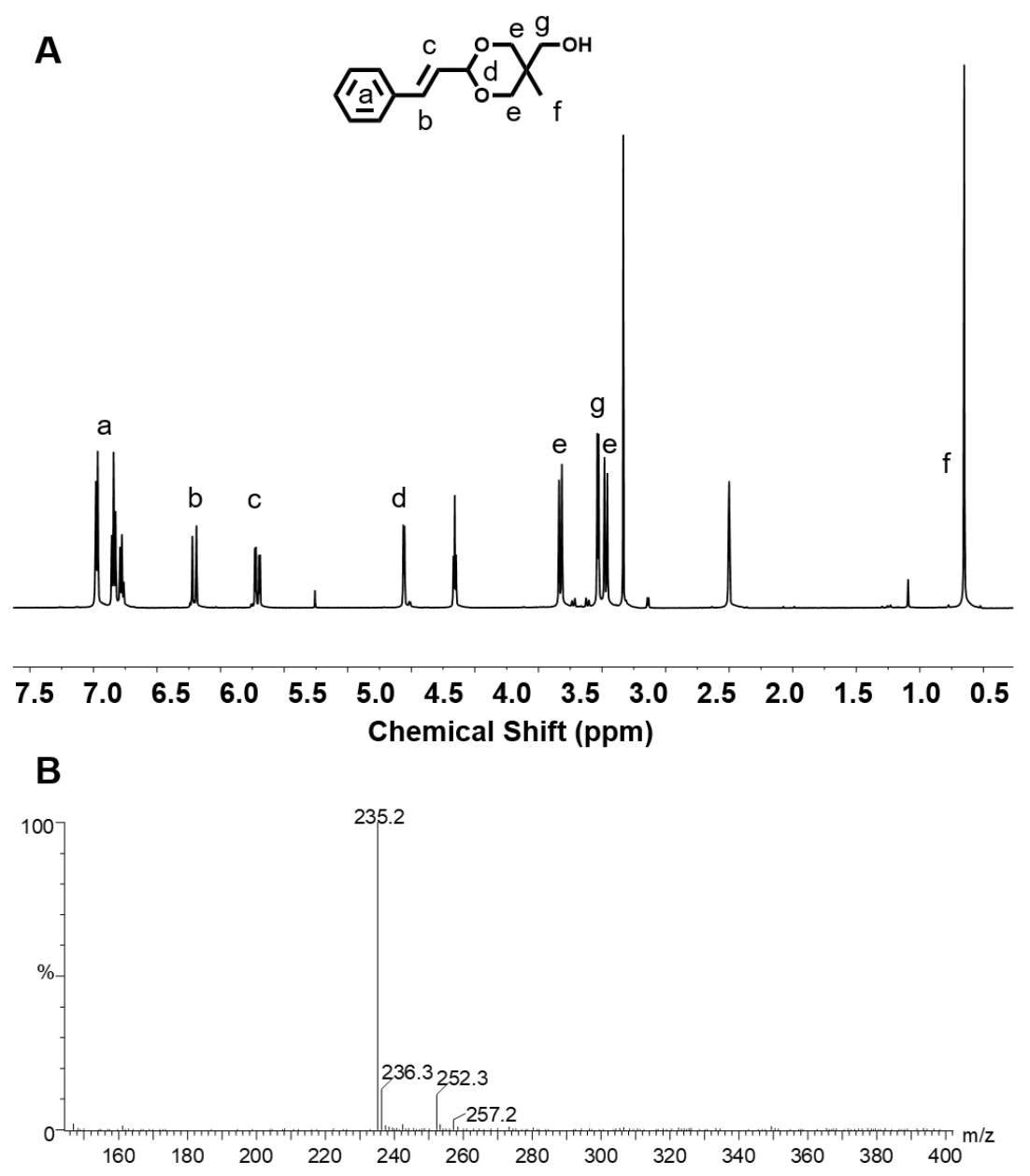

Figure S1. (A) ${ }^{1} \mathrm{H}$ NMR spectrum and (B) ESI-MS spectrum of acetal modified CA derivative. 
A<smiles>CC(=Cc1ccccc1)C1OOC(O)(COC(=O)CCC(=O)O)C(C)(I)O1</smiles>
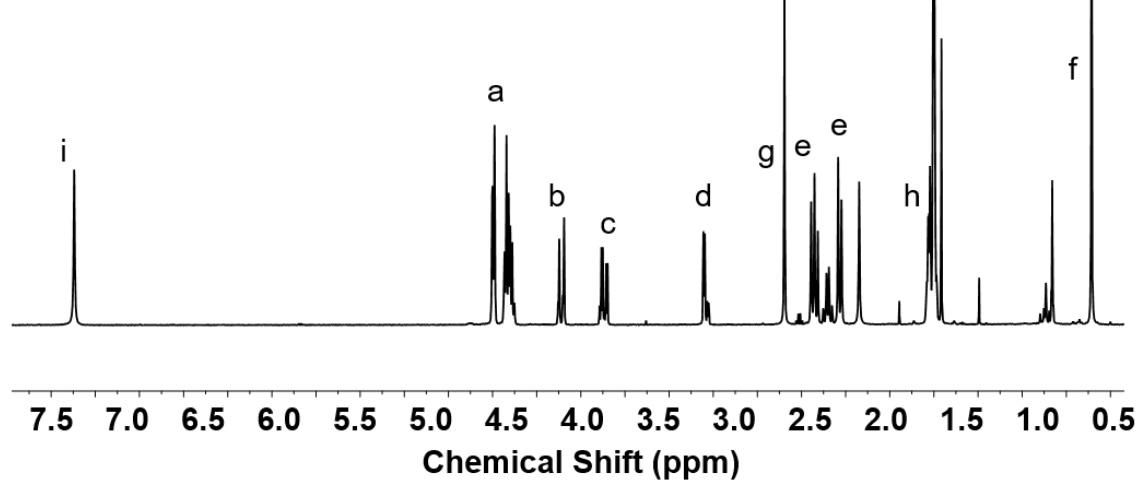

B

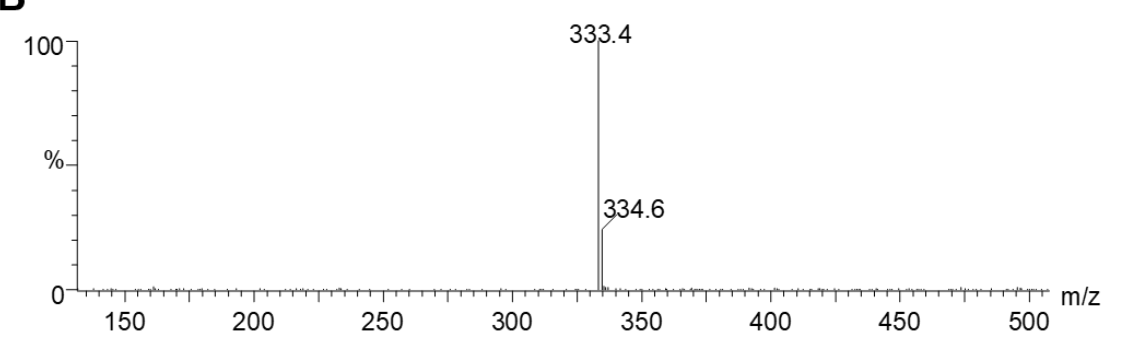

Figure S2. (A) ${ }^{1} \mathrm{H}$ NMR spectrum and (B) ESI-MS spectrum of CA derivative (3).

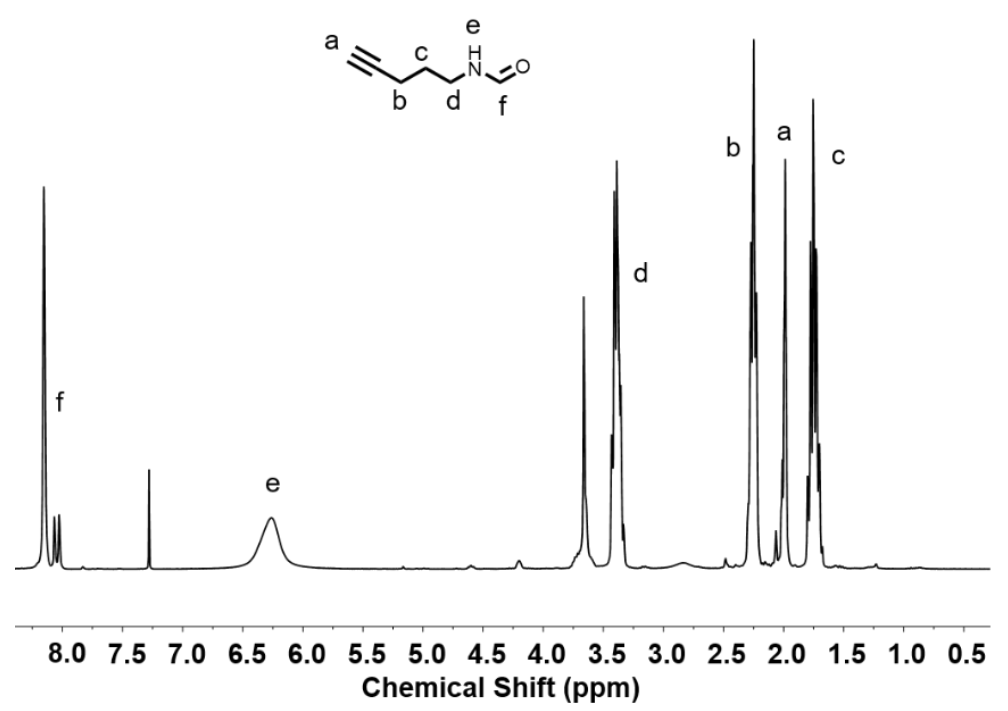

Figure S3. ${ }^{1} \mathrm{H}$ NMR spectrum of 5-formylaminopent-1-yne in $\mathrm{CDCl}_{3}$. 


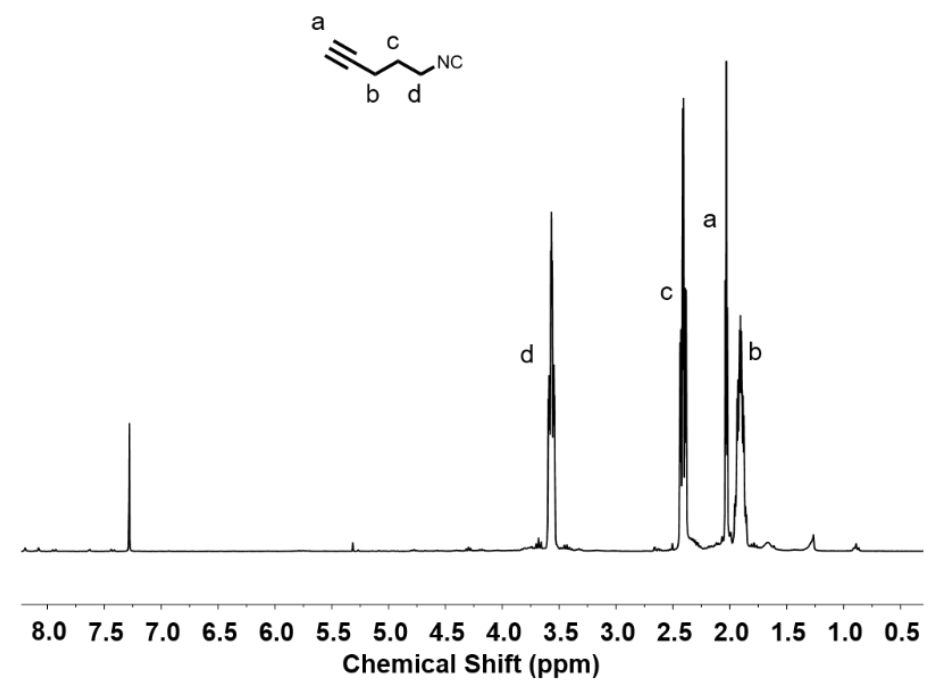

Figure S4. ${ }^{1} \mathrm{H}$ NMR spectrum of 5-isocyanopent-1-yne in $\mathrm{CDCl}_{3}$.

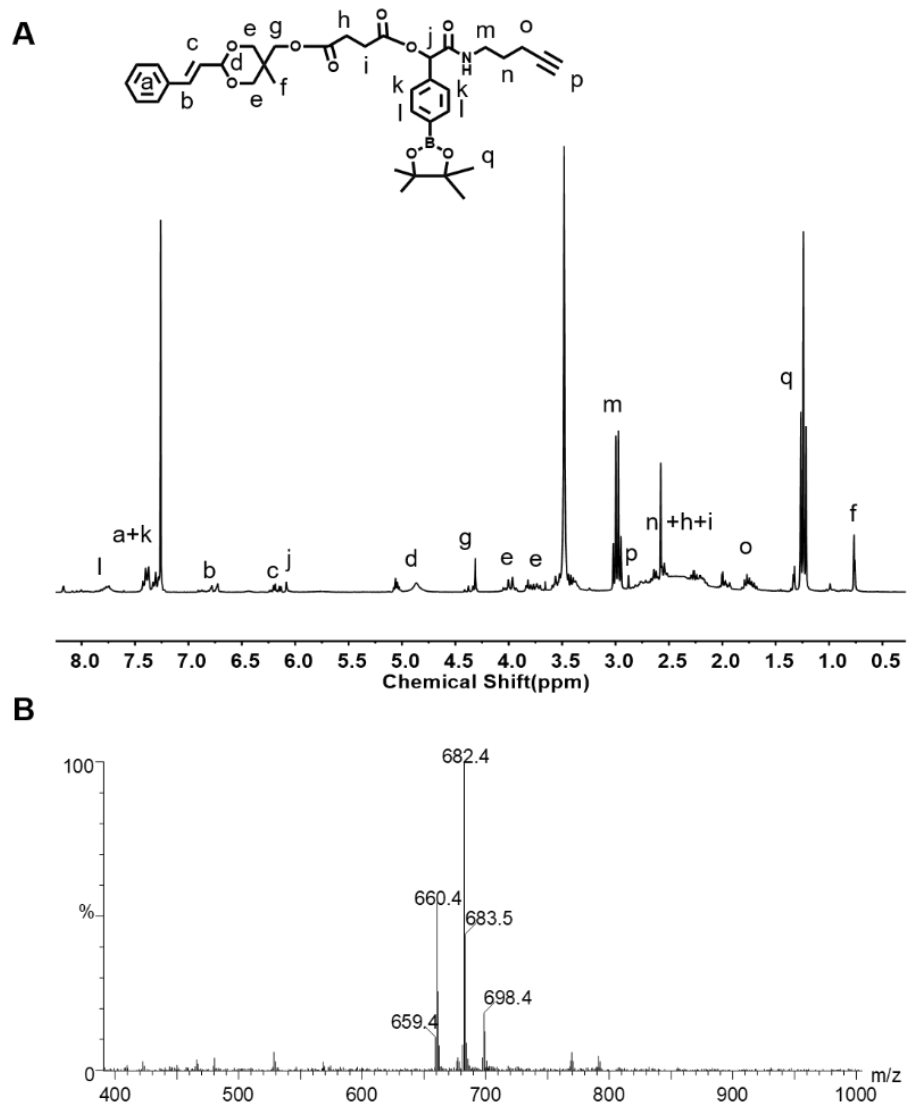

Figure S5. (A) ${ }^{1} \mathrm{H}$ NMR spectrum and (B) ESI-MS spectrum of PBCA. 


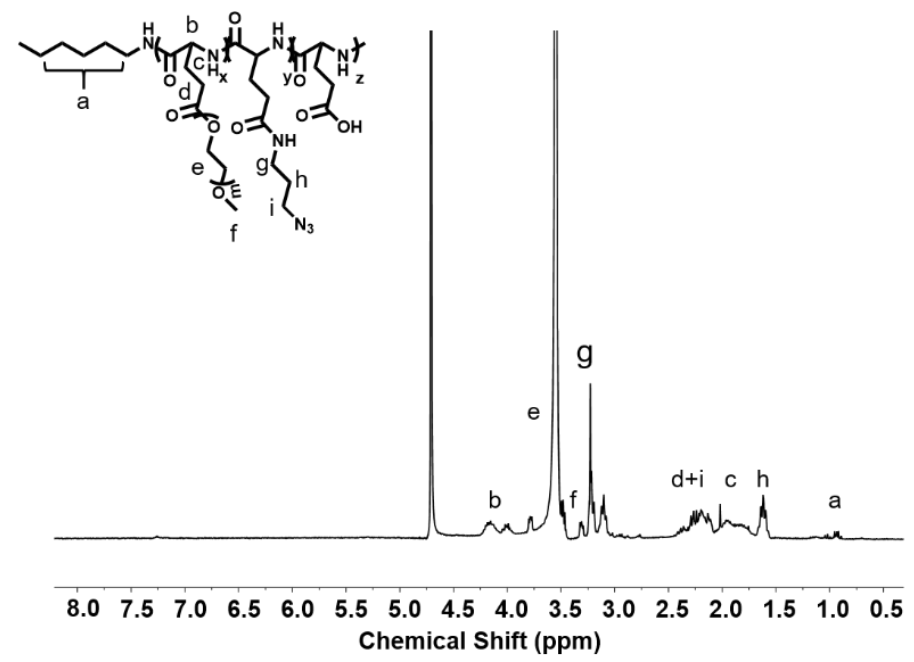

Figure S6. ${ }^{1} \mathrm{H}$ NMR spectrum of $\mathrm{PLG}_{-} \mathrm{N}_{3}$ in $\mathrm{D}_{2} \mathrm{O}$.

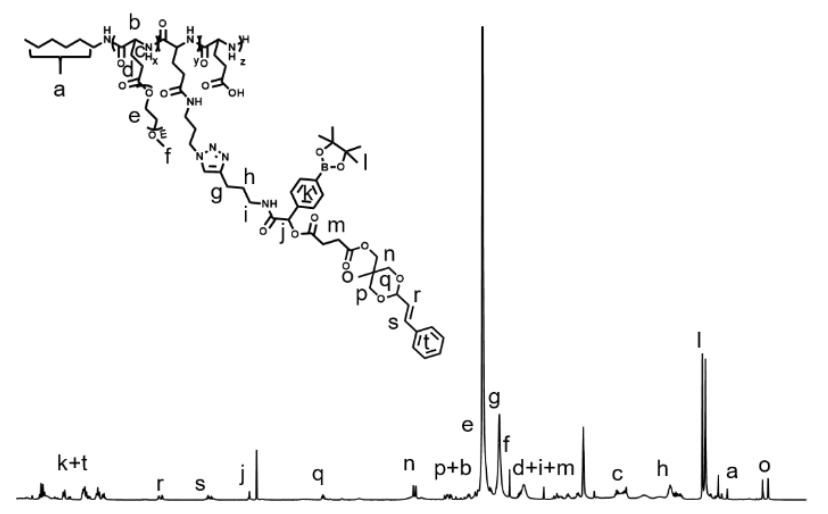

$\begin{array}{llllllllllllllll}8.0 & 7.5 & 7.0 & 6.5 & 6.0 & 5.5 & 5.0 & 4.5 & 4.0 & 3.5 & 3.0 & 2.5 & 2.0 & 1.5 & 1.0 & 0.5\end{array}$ Chemical Shift (ppm)

Figure S7. ${ }^{1} \mathrm{H}$ NMR spectrum of TSEOP in DMSO- $d_{6}$.

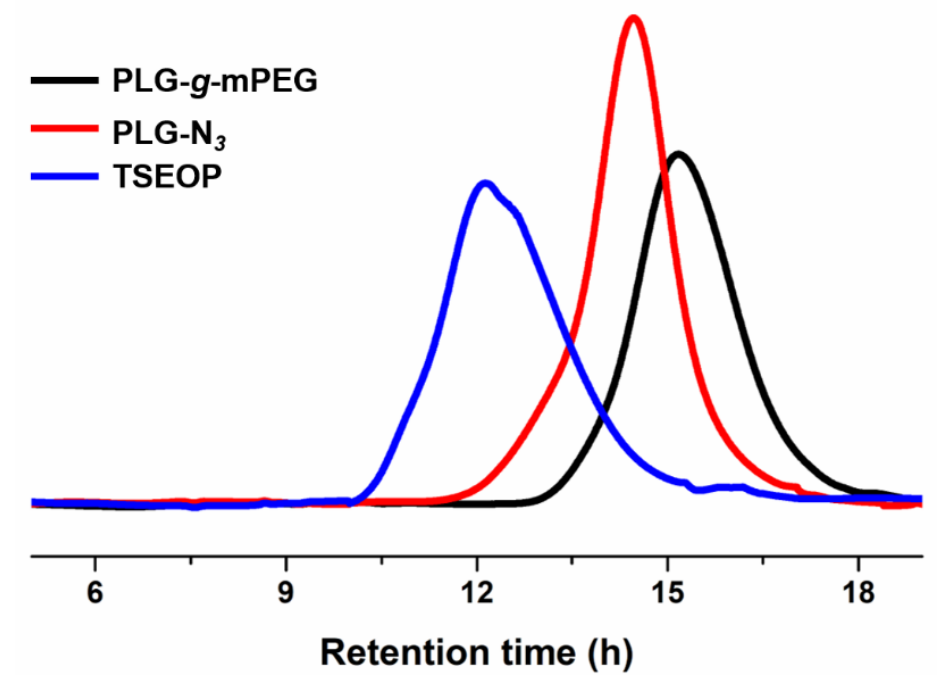

Figure S8. GPC curves of PLG- $g$-mPEG, PLG-N 3 and TSEOP. 
A TSOEP in $\mathrm{pH} 7.4 \mathrm{~PB}$

B TSOEP in $\mathrm{pH} 7.4 \mathrm{~PB}$
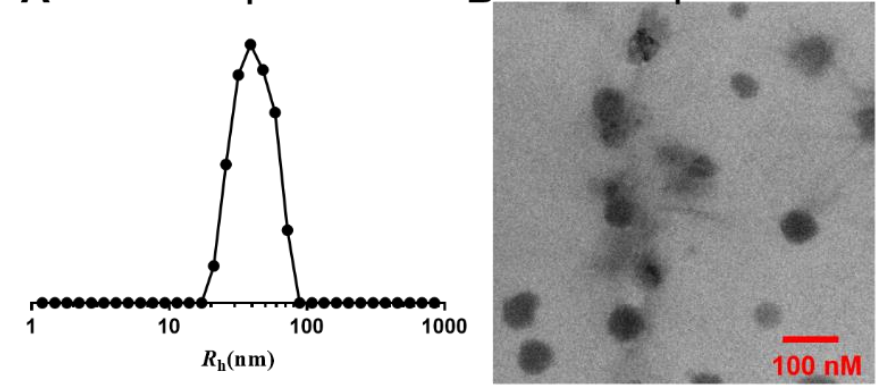

C

TSOEP in pH $6.8 \mathrm{~PB}+100 \mathrm{mM} \mathrm{H}_{2} \mathrm{O}_{2}$

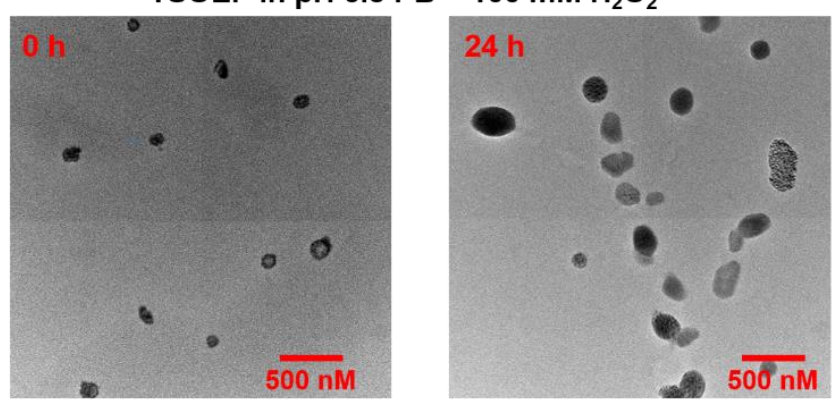

Figure S9. Hydrodynamic radius $\left(R_{\mathrm{h}}\right)$ and morphologies of TSEOP nano-micelles. (A) Hydrodynamic radii $\left(R_{\mathrm{h}}\right)$ of TSEOP in $\mathrm{pH} 7.4$ PB. (B) TEM image of TSEOP nanomicelles in pH 7.4 PB. (C) TEM images of TSEOP after incubated in pH 6.8 PB with $100 \mathrm{mM}$ for 0 and $24 \mathrm{~h}$.

A

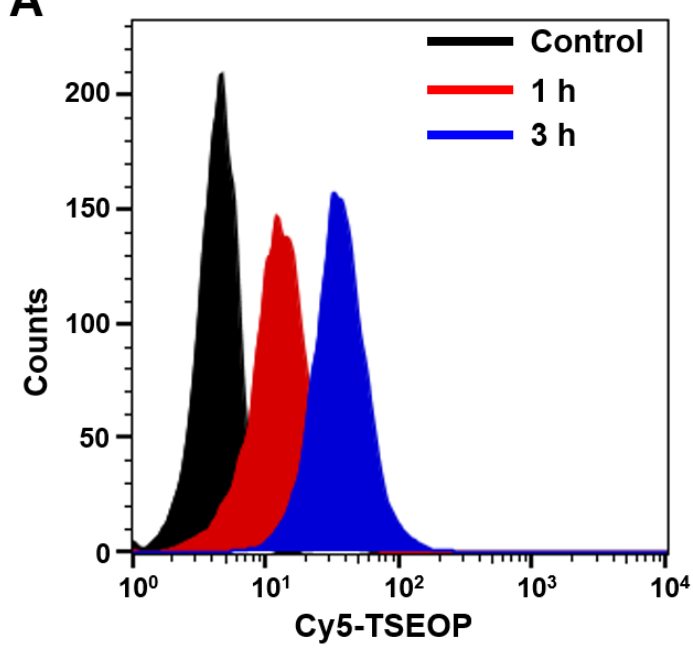

B

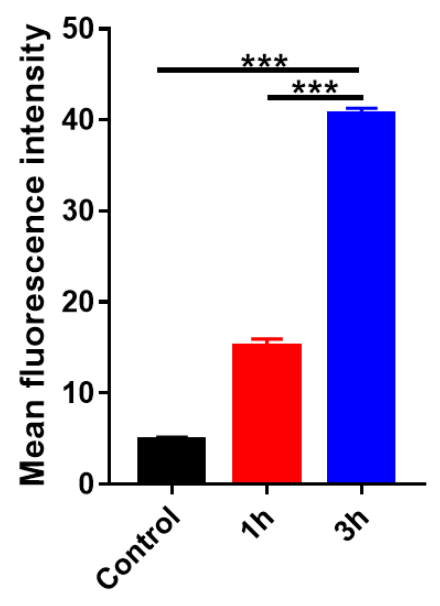

Figure S10. (A) Flow cytometric analysis of cellular internalization of Cy5-TSEOP incubated with CT26 cells for $1 \mathrm{~h}$ or $3 \mathrm{~h}$ at $37^{\circ} \mathrm{C}$. (B) Mean fluorescence intensities of CT26 cells treated as described in (A). The data are expressed as mean $\pm \mathrm{SD}, * * * \mathrm{p}$ $<0.001$. 


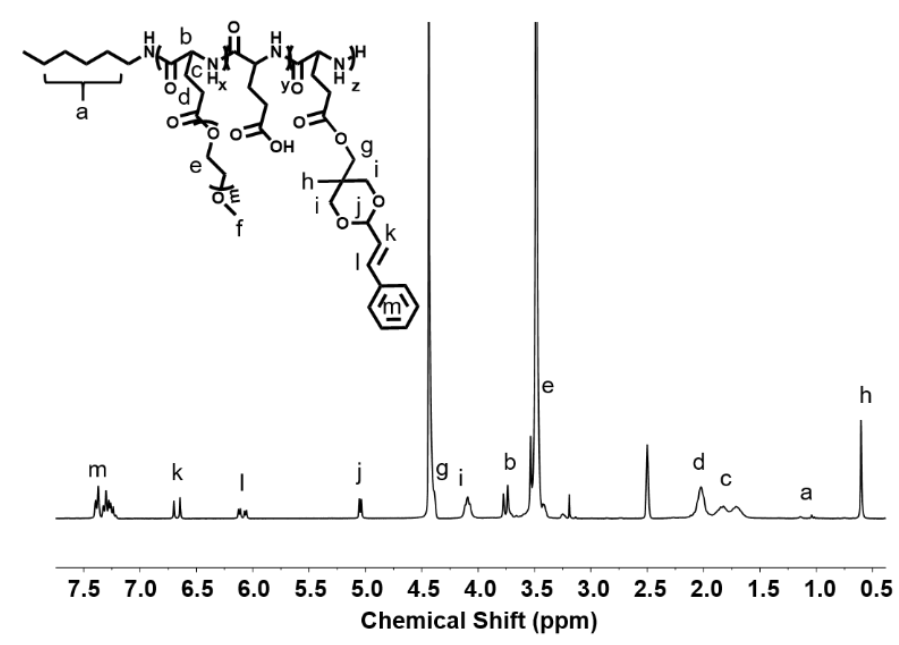

Figure S11. ${ }^{1} \mathrm{H}$ NMR spectrum of P-CA in DMSO- $d_{6} / \mathrm{D}_{2} \mathrm{O}(v: v=1: 1)$.

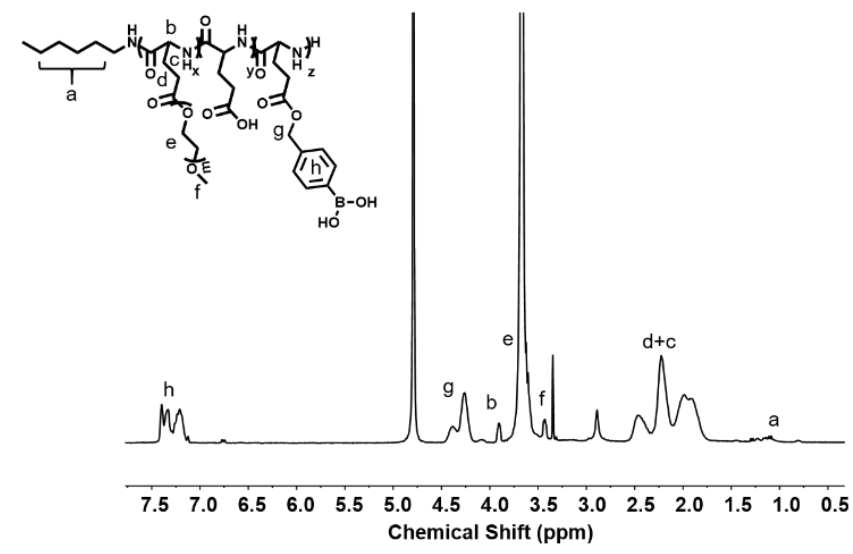

Figure S12. ${ }^{1} \mathrm{H}$ NMR spectrum of P-PBA in $\mathrm{D}_{2} \mathrm{O}$.

A CT26 $24 \mathrm{~h}$

B

$4 \mathrm{~T} 124 \mathrm{~h}$
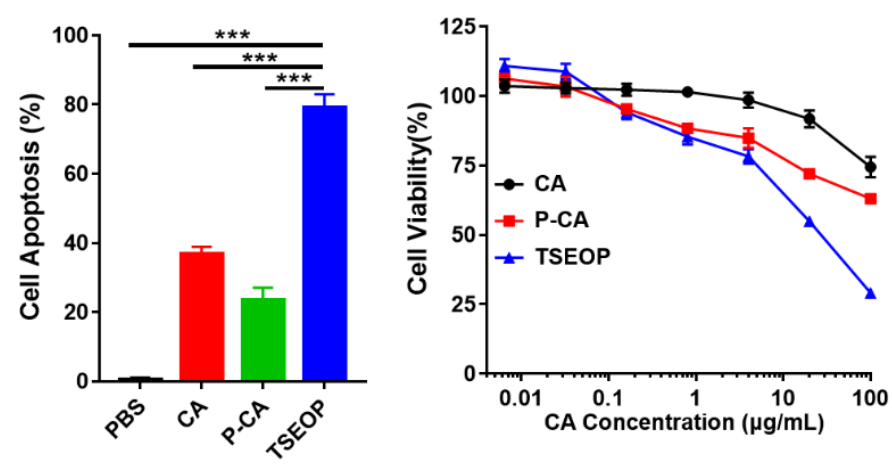

Figure S13. (A) In vitro apoptosis assay results of CT26 cells after incubation with PBS, CA, P-CA and TSEOP for $24 \mathrm{~h}$ post-treatment, Mean \pm S.D., $n=3$. (B) In vitro cytotoxicities of free CA, P-CA and TSEOP to 4T1 cells after incubation for $24 \mathrm{~h}$. Mean \pm S.D., $n=5$. 


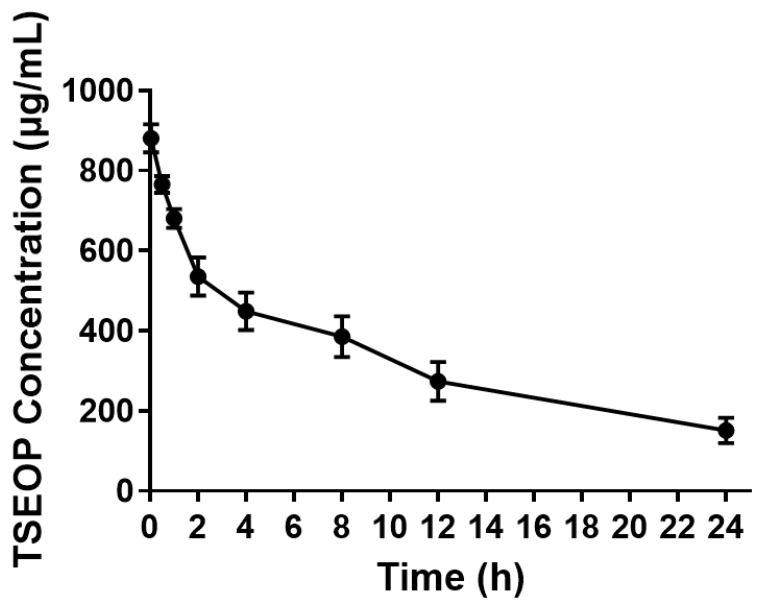

Figure S14. Pharmacokinetic results of TSEOP in SD rats. Data were shown as means $\pm \operatorname{SD}(n=3)$.

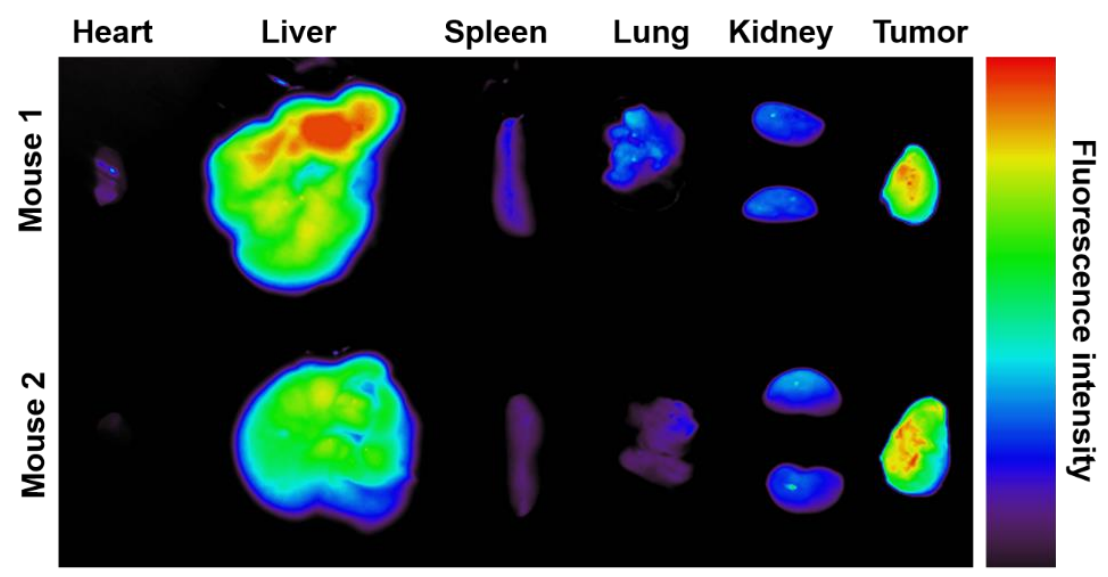

(Color scale: $0.1-3.0 \times 10^{11} \mathrm{p} / \mathrm{s} / \mathrm{cm}^{2} / \mathrm{sr}$ )

Figure S15. Fluorescence images of major organs and tumors at $24 \mathrm{~h}$ post-injection of Cy5-TSEOP.

A

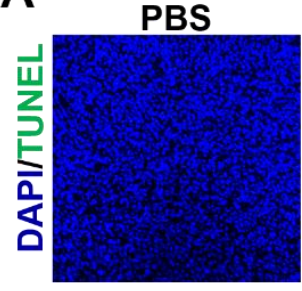

CA

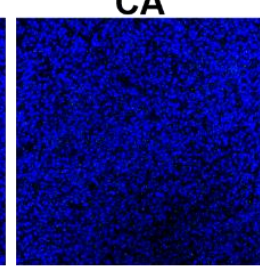

P-CA

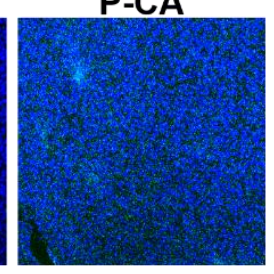
TSOEP

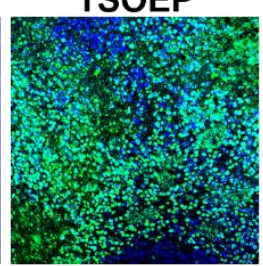

B

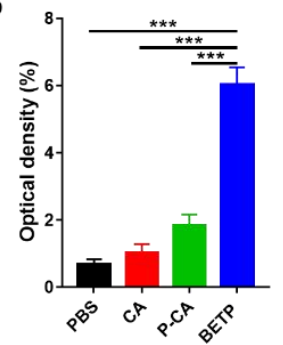

Figure S16. (A) TUNEL staining of CT26 tumor sections after various treatments. (B)

Relative optical density statistics of tumor section from TUNEL staining; $n=3$. 

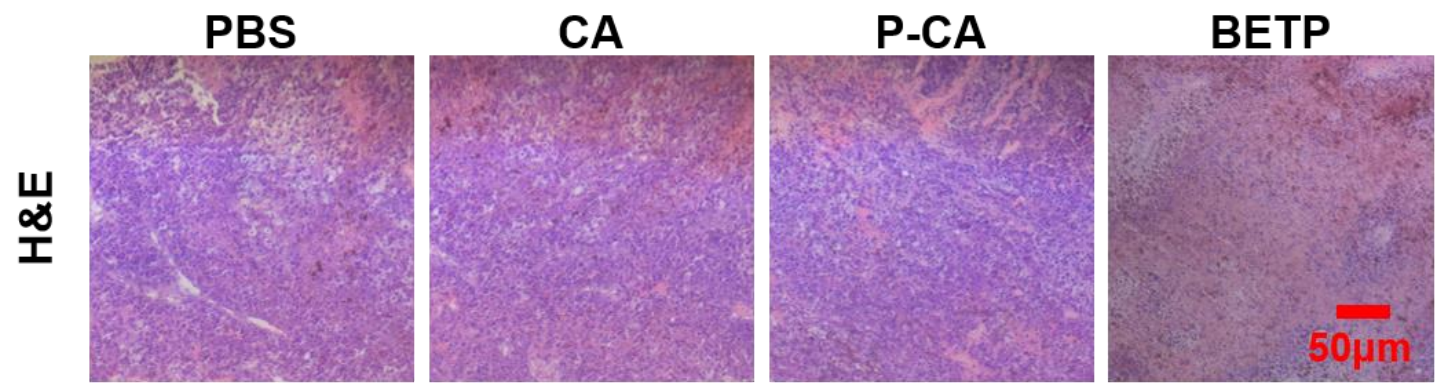

Figure S17. H\&E staining of tumor sections from CT26 tumor bearing mice after various treatments. 
A

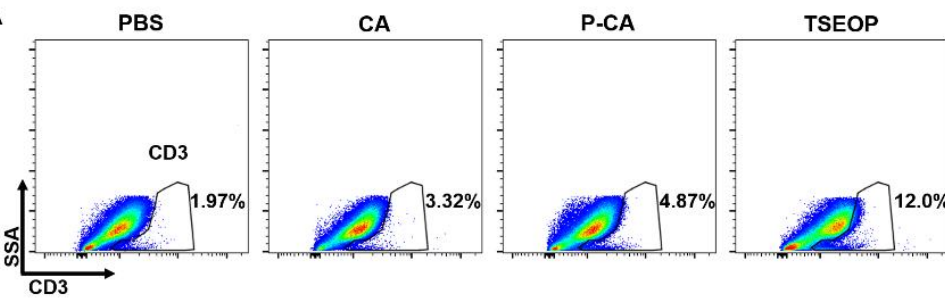

B
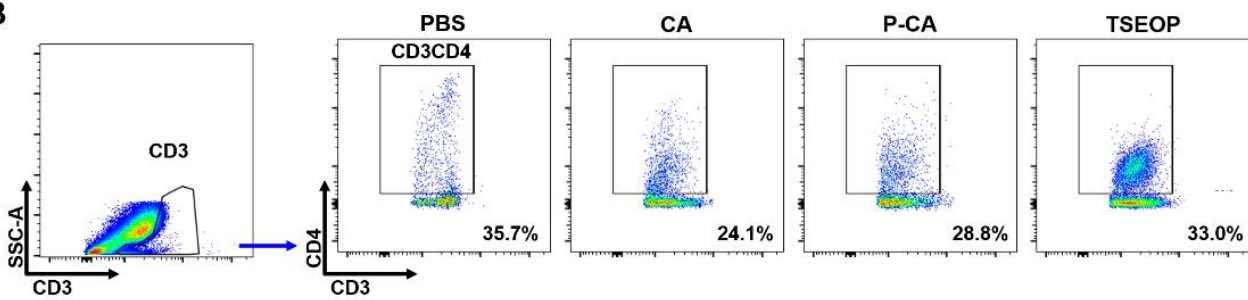

C
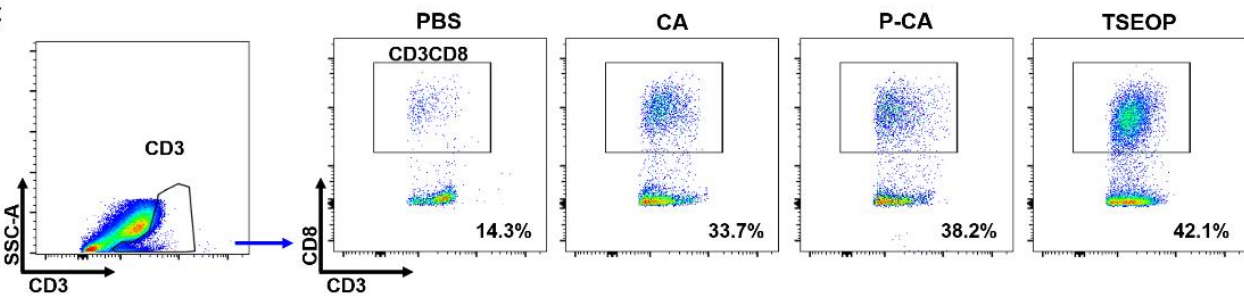

D
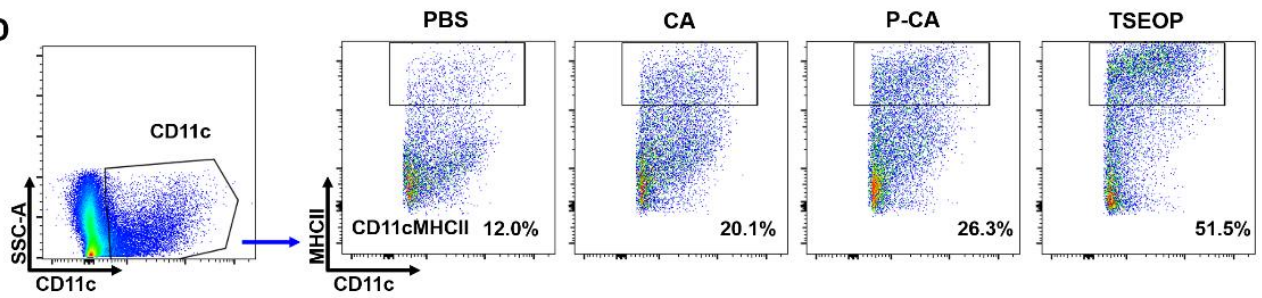

E
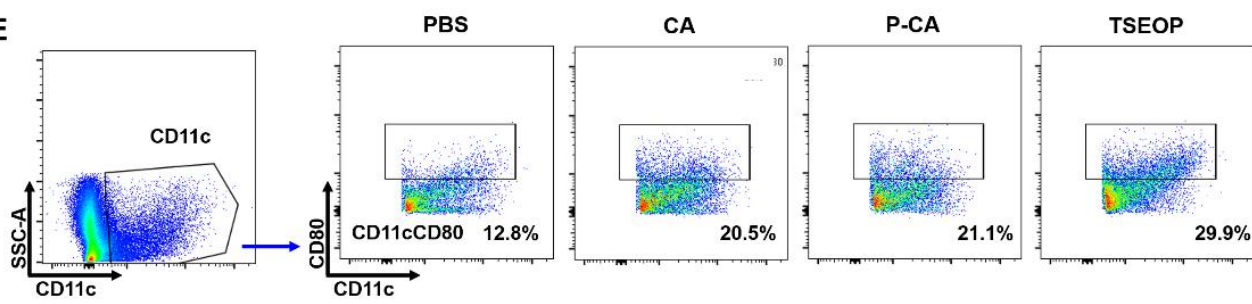

$\mathbf{F}$
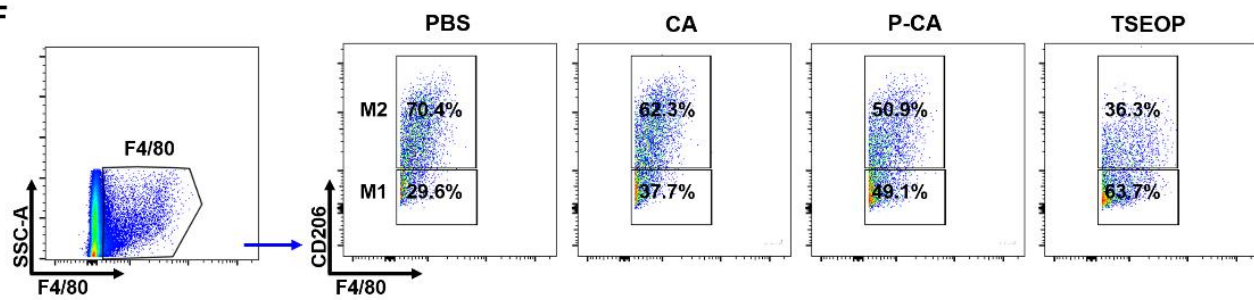

Figure S18. Gating strategies and representative flow cytometric analysis images of flow cytometry analysis of the murine colorectal model (CT26). (A) Gating strategies for $\mathrm{CD}^{+} \mathrm{T}$ cells $\left(\mathrm{CD} 3^{+} \mathrm{CD} 4^{+}\right.$population). (B) Gating strategies for $\mathrm{CD}^{+} \mathrm{T}$ cells $\left(\mathrm{CD}^{+} \mathrm{CD}^{+}\right.$population). (C) Gating strategies for $\mathrm{CD}^{+} \mathrm{T}$ cells $\left(\mathrm{CD}^{+} \mathrm{CD}^{+}\right.$ population). (D) Gating strategies for $\mathrm{CD} 11 \mathrm{c}^{+} \mathrm{MHCII}{ }^{+}$DCs. (E) Gating strategies for 


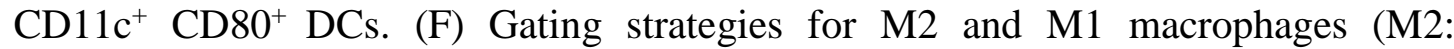
F4/80 ${ }^{+} \mathrm{CD}^{2} 26^{+}$population; M1: F4/80 ${ }^{+} \mathrm{CD} 206^{-}$population).

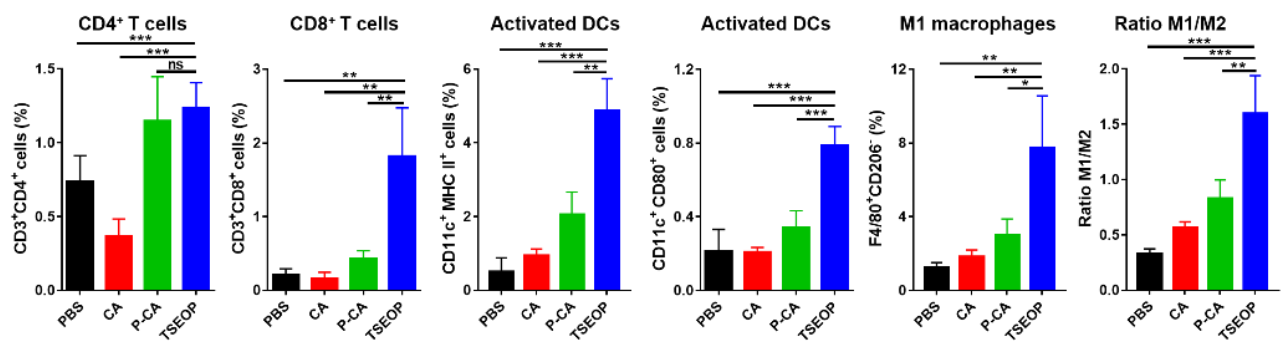

Figure S19. Flow cytometry analysis of 4T1 tumors after receiving different treatments; $n=4$. Results are presented as means $\pm \mathrm{SD} ; * \mathrm{p}<0.05, * * \mathrm{p}<0.01, * * * \mathrm{p}<0.001$. 


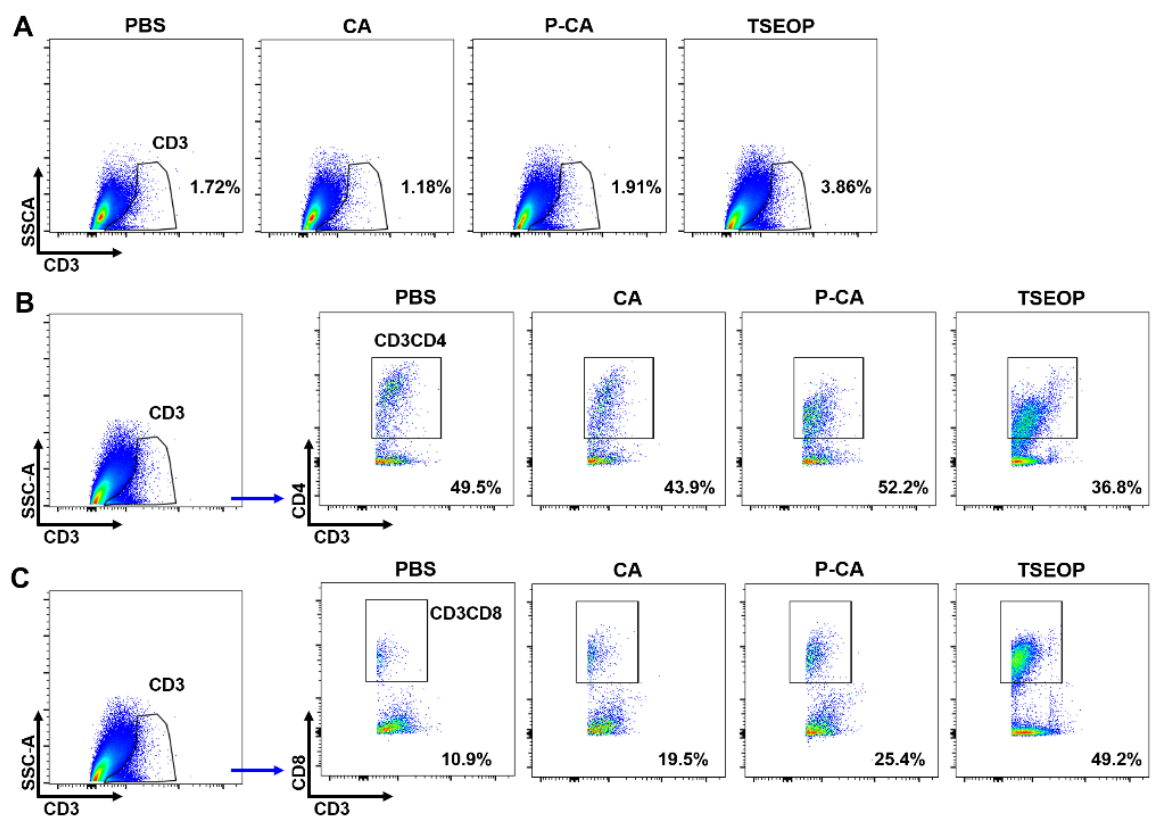

D
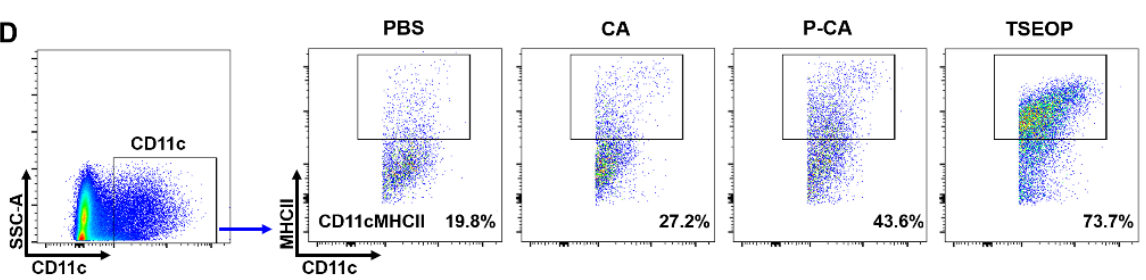

E

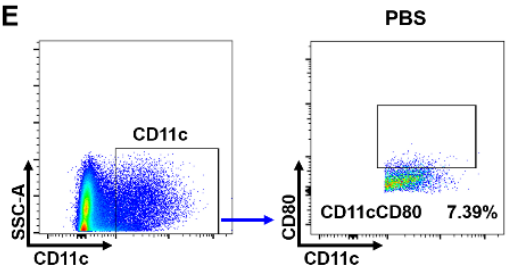

CA
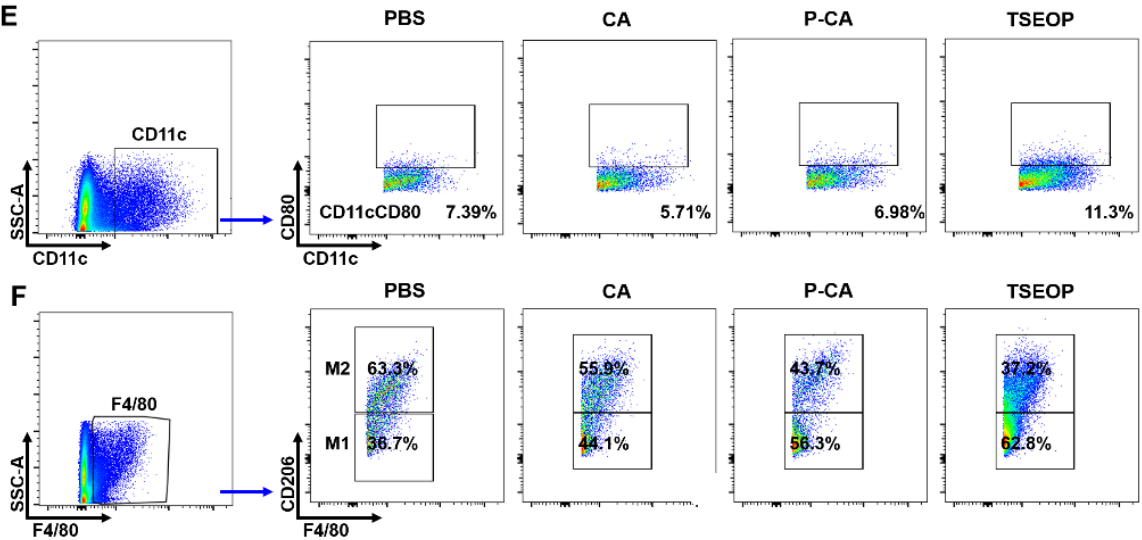

Figure S20. Gating strategies and representative flow cytometric analysis images of flow cytometry analysis of the murine breast cancer model (4T1). (A) Gating strategies for $\mathrm{CD}^{+} \mathrm{T}$ cells $\left(\mathrm{CD}^{+} \mathrm{CD}^{+}\right.$population). (B) Gating strategies for $\mathrm{CD} 3^{+} \mathrm{T}$ cells $\left(\mathrm{CD}^{+}{ }^{+} \mathrm{CD} 4^{+}\right.$population). (C) Gating strategies for $\mathrm{CD} 8^{+} \mathrm{T}$ cells $\left(\mathrm{CD} 3^{+} \mathrm{CD} 8^{+}\right.$ population). (D) Gating strategies for $\mathrm{CD} 11 \mathrm{c}^{+} \mathrm{MHCII}{ }^{+} \mathrm{DCs}$. (E) Gating strategies for CD11 ${ }^{+}$CD80 $0^{+}$DCs. (F) Gating strategies for M2 and M1 macrophages (M2: $\mathrm{F} 4 / 80^{+} \mathrm{CD} 206^{+}$population; $\mathrm{M} 1$ : $\mathrm{F} 4 / 80^{+} \mathrm{CD} 206^{-}$population). 

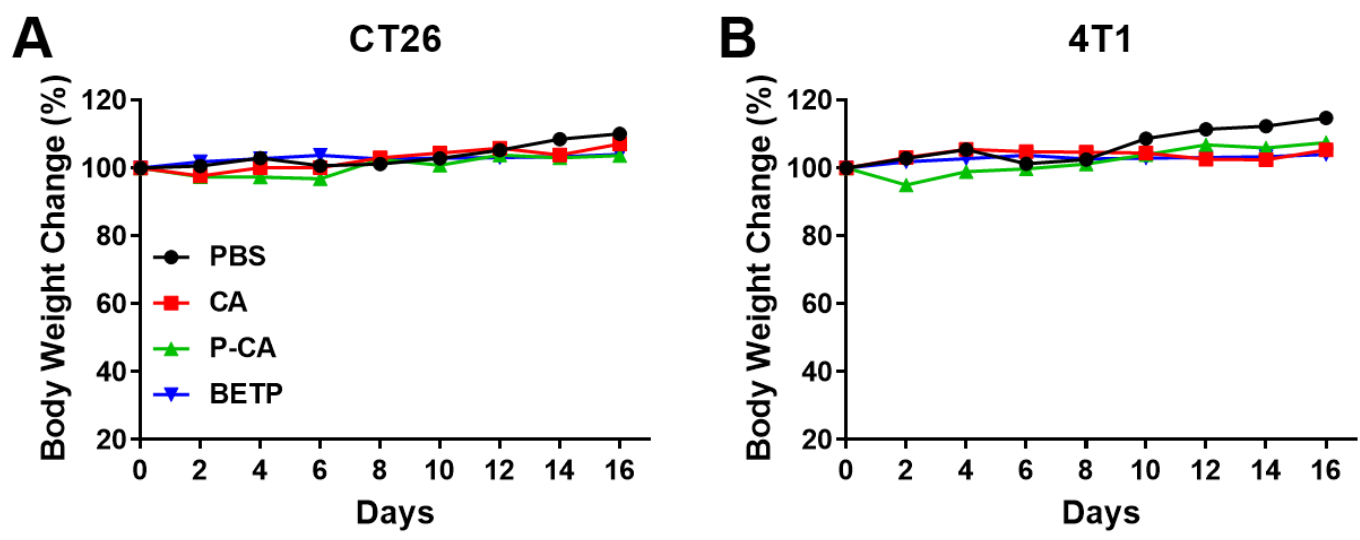

Figure S21. Body weight changes of CT26 (A) and 4T1 (B) tumor-bearing mice after receiving different treatments; $n=5$. Results are presented as mean $\pm \mathrm{SD}$;

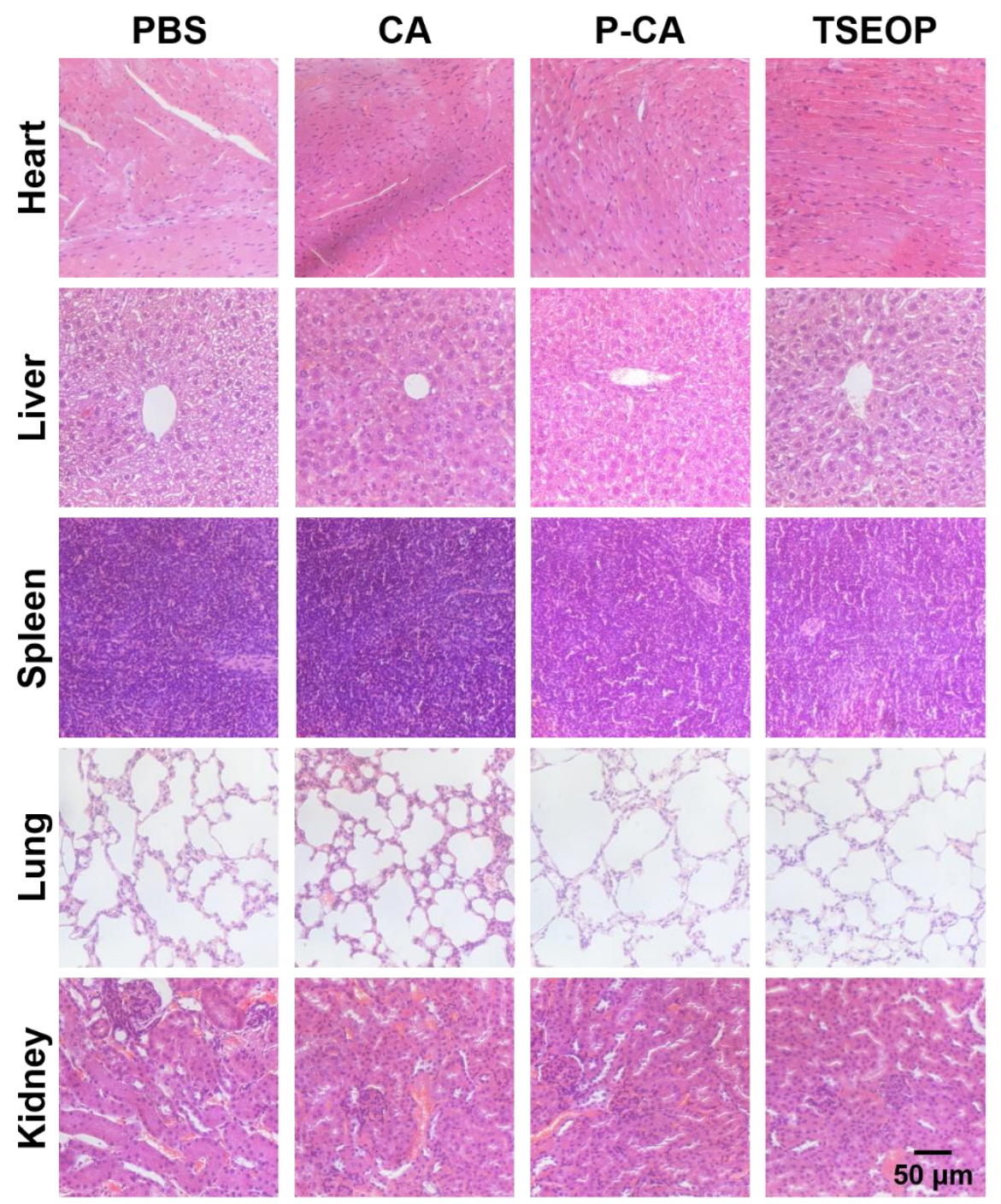

Figure S22. Histological analysis of different organs (heart, liver, spleen, lung and kidney) in CT26 model after various treatments. 

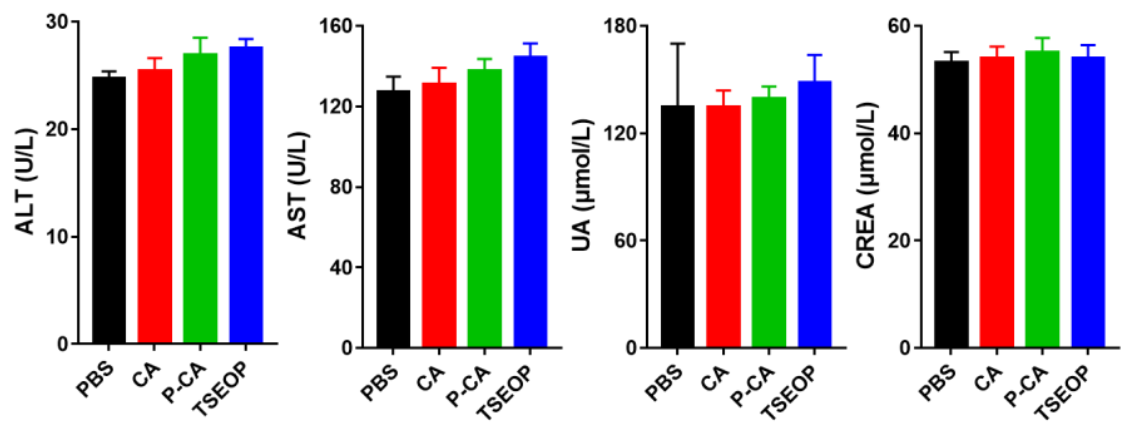

Figure S23. Blood chemistry analysis of the CT26 tumor bearing mice after various treatments . Measurements were carried out on day 16; $n=3$.

Table S1. Antibodies used in the study.

\begin{tabular}{|c|c|c|c|}
\hline Antibodies & Company & Catalog & Application \\
\hline FITC anti-mouse CD3 Antibody & BioLegend & 100203 & flow cyt \\
\hline PE/Cy7 anti-mouse CD4 Antibody & BioLegend & 100422 & flow cyt \\
\hline APC anti-mouse CD8a Antibody & BioLegend & 100712 & flow cyt \\
\hline PE anti-mouse CD11c Antibody & BioLegend & 102026 & flow cyt \\
\hline PerCP/Cy5.5 anti-mouse CD80 & BioLegend & 101918 & flow cyt \\
\hline Antibody & & & \\
\hline FITC anti-mouse CD206 Antibody & BioLegend & 141704 & flow cyt \\
\hline PerCP/Cy5.5 anti-mouse F4/80 Antibody & BioLegend & 123128 & flow cyt \\
\hline APC/Cy7 anti-mouse I-A/I-E (MHCII) & BioLegend & 107628 & flow cyt \\
\hline Antibody & & & \\
\hline Cy5 anti-mouse CRT Antibody & Abcam & Ab124964 & flow cyt IF \\
\hline anti-mouse HMGB1 Antibody & Abcam & Ab124964 & flow cyt IF \\
\hline Cy5 Goat anti-Rabbit IgG & ABclonal & AS011 & IF \\
\hline
\end{tabular}

\section{Reference:}

1. Ding, J.; Zhuang, X.; Xiao, C.; Cheng, Y.; Zhao, L.; He, C.; Tang, Z.; Chen, X., Preparation of photo-cross-linked $\mathrm{pH}$-responsive polypeptide nanogels as potential 
carriers for controlled drug delivery. Journal of Materials Chemistry 2011, 21 (30), 11383-11391.

2. Zhang, J.; Zhang, M.; Du, F.-S.; Li, Z.-C., Synthesis of Functional Polycaprolactones via Passerini Multicomponent Polymerization of 6-Oxohexanoic Acid and Isocyanides. Macromolecules 2016, 49 (7), 2592-2600.

3. Song, W. T.; Tang, Z. H.; Zhang, D. W.; Zhang, Y.; Yu, H. Y.; Li, M. Q.; Lv, S. X.; Sun, H.; Deng, M. X.; Chen, X. S., Anti-tumor efficacy of c(RGDfK)-decorated polypeptide-based micelles co-loaded with docetaxel and cisplatin. Biomaterials 2014, 35 (9), 3005-3014.

4. Si, X.; Ma, S.; Xu, Y.; Zhang, D.; Shen, N.; Yu, H.; Zhang, Y.; Song, W.; Tang, Z.; Chen, X., Hypoxia-sensitive supramolecular nanogels for the cytosolic delivery of ribonuclease A as a breast cancer therapeutic. Journal of controlled release : official journal of the Controlled Release Society 2020, 320, 83-95. 